\title{
Development of the Internal Electricity Market in Europe
}

\author{
Leonardo Meeus ${ }^{\mathrm{a},{ }^{*}, \text { Konrad Purchala }^{\mathrm{a}}, \text { Ronnie Belmans }}{ }^{\mathrm{a}}$ \\ ${ }^{a}$ Department of Electrical Engineering (ESAT-ELECTA) \\ Kasteelpark Arenberg 10, 3001 Leuven, Belgium \\ leonardo.meeus@esat.kuleuven.ac.be, konrad.purchala@esat.kuleuven.ac.be, \\ ronnie.belmans@esat.kuleuven.ac.be
}

\begin{abstract}
This paper starts from the observation that the Member States of the European Union have similar electricity market architectures but that these markets are weakly integrated. The authors start with a discussion of the regulation that is driving the ongoing liberalization process and then move on with a discussion of the resulting market architecture. The status of the internal electricity market in Europe is evaluated in terms of market structure, development and design. It is argued that there is a lot of potential in improving the links between Member State submarkets, making better use of existing grid infrastructure. It is also argued that investments in grid bottlenecks are necessary but that existing regulation is not adequate to ensure and coordinate cross-border transmission investments.
\end{abstract}

Index Terms-- Regulation - Power systems - Economics

\footnotetext{
* Corresponding author. Tel.: ++32-(0)16/321722; Fax: ++32-(0)16/321985; E-mail address: leonardo.meeus@esat.kuleuven.ac.be. This is the post-print edition of this article: Meeus, L., Purchala, K., Belmans, R., 2005. Development of the internal electricity market in Europe, Electricity Journal, 18(6), pp. 25-35.
} 


\section{INTRODUCTION}

In the past, the electricity industry has been organized as vertically integrated monopolies that were sometimes also state owned. The growing ideological and political disaffection towards vertically integrated monopolies and the liberalization successes in other network industries have lead to liberalization initiatives world wide in the electricity industry. Vertically integrated utilities have been vertically separated or unbundled and barriers to entry in generation and supply are being removed to create competition, seen as a vehicle to increase the competitiveness of the electricity industry. ${ }^{1}$

Already in 1979, the US Public Utility Regulatory Policy Act opened the door for new entrants in generation. Further restructuring of the electricity sector in the US came later in the nineties. Since then, some States have gradually also been introducing competition in supply, without federal regulation nor legislation. As a result, the US electricity industry today is a patchwork with on one extreme States that are fully liberalized and on the other extreme States where nothing happened yet. Moreover, the process has been slowed down because of the California crises with the collapse of Enron in $2001^{2}$ and the 2003 New York black out.

In a liberalized market, the good electricity is the result of a bundle of tasks performed and services provided by different players. Well functioning markets are therefore a critical success factor of the liberalization. In many cases, this has triggered public initiative with governments creating mandatory wholesale markets, called power pools. This was for instance the case in England and Wales, Alberta, Chile, Argentina and in the United States in Pennsylvania, New Jersey and Maryland (PJM). Pools have always existed. Vertically integrated utilities used a pool system to enable a better technical dispatch, minimizing generation costs and taking into account network constraints. In a liberalized market, generators can take into account a lot of technical aspects by submitting complex offers to the power pool. Due to the complex nature of these offers, the price determination mechanism involves a complex optimization calculation with a low level of transparency. The necessity of side payments on top of the pool price to settle the market adds to the non-transparent nature of these mandatory wholesale markets. 
The liberalization in the European Union (EU) is a top down process driven by the Directives of the European Parliament and of the Council ${ }^{3}$. The Directives lay down the general conditions that should be in place to assure the creation of a single internal electricity market (IEM) in Europe, but refrain from designing a concrete market. Given this freedom, most European countries have chosen to keep centralized components to a minimum and to leave market organization to the dynamics of private initiative. In this paper, the authors give their viewpoint on how the IEM can develop further. First, European regulation and market architecture are discussed. Second, the status of the IEM is described. Third, the necessity of European regulation or coordinated regulatory actions to ensure the necessary investments in grid bottlenecks is underlined. Finally, the authors identify 2 possible stages for the further development of the IEM, requiring an increasing degree of coordination and harmonization.

Parallel to the restructuring of the energy industry in Europe, a lot of environmental and public interest policies have been implemented. Although these policies serve a good purpose on their own, they have been implemented cost inefficiently and often conflict with the creation of the IEM. As a consequence, the competitiveness of the energy industry is seriously threatened, which could lead to mistrust of the general public and especially large electricity consumers in the liberalization process in Europe. This problem has been underlined at the last Eurelectric conference in Brussels and needs to be addressed, but is outside the scope of this paper.

\section{EUROPEAN REGULATION}

The EU Treaties of Rome (1957) and Maastricht (1993) laid the foundation of the creation of an internal market in the European Union with free movement of people, goods and capital. In the past, supply of electricity was however considered as a service of general economic interest and consequently not subject to the normal rules of competition as established by the EU Treaties. The European Court of Justice ruled on several occasions that electricity is a good, putting an end to the consideration of electricity being a service. The liberalization process put into force in 1996 by Directive 96/92/EC, lead to the unbundling of activities. Because of the separate legal treatment of the commodity electricity (=the good) and the supply of electricity (=the services), it is no longer sufficient to argue that electricity is a good alone ${ }^{4}$. In 2003 Directive 2003/54/EC was put into force, replacing Directive 96/92/EC. 
Besides the Treaties and Directives, the following organizations are driving the liberalization process:

- the Directorate-Generates of the European Commission (EC) responsible for developing and implementing European policies in their overlapping fields: DG Energy and Transport (DGTREN), DG Competition and DG Environment;

- the Florence forum, which is now in Rome, where parties involved discuss twice a year the creation of the IEM;

- the European Regulators Group for Electricity and Gas (ERGEG);

- and voluntary European associations like Eurelectric (industry: generators and suppliers), ETSO (transmission system operators), IFIEC (consumers), EFET (traders), Europex (power exchanges), the Council of European Energy Regulators (CEER) and UCTE, Nordel, GBTSO, ATSOI and IPS/UPS (transmission system operators part of the respective synchronous areas);

In what follows, the 3 major implementation aspects of the Directives are discussed, being market opening, third party access and the system operator. As said in the introduction, a discussion of public service obligations and environmental regulation affecting the creation of the IEM is outside the scope of this paper.

First, Directive 96/92/EC introduced the concept of 'eligible consumers', being consumers who have the legal capacity to contract volumes of electricity from any supplier. The Directive aimed at a slow, gradual and partial opening of the Member States' electricity markets so that more and more generators and consumers have the opportunity to freely negotiate the purchase and sales of electricity. With the new Directive 2003/54/EC, put into force in 2003 and replacing the first Directive the process is dramatically accelerated and all non-households customers are eligible from 1 July 2004 and all consumers will be eligible from 1 July 2007.

Second, suppliers and generators need to be assured they will have access to the grid to settle negotiated electrical energy transactions for delivering electric energy. Directive 96/92/EC included 3 third party access models, being negotiated third party access (nTPA), regulated third party access (rTPA), and the single buyer model. The single buyer model allows the creation of a mandatory power pool for generators with for instance the system operator acting as a 'single buyer' in the pool. In the rTPA 
model, prices for access to the network are regulated, while in the nTPA they may be subject to negotiations. Different access and tariff regimes have proven to be one of the main obstacles to the creation of the IEM. Directive 2003/54/EC therefore introduces one regime, being rTPA, and the requirement to appoint a regulator, who has to approve the tariffs, monitor congestion management and act as a dispute settlement authority.

Third, the system operator plays a crucial role, also in a liberalized market. The system operator provides the critical coordination service: he must keep the balance between generation and supply, keep the voltage at the right level, and restart the system when it suffers a complete collapse. The system operator carries out these basic functions by purchasing what are called ancillary services, which can be supplied by generators, but also by the demand side. In order to ensure transparency of the market and avoid discrimination, network activities and supply and generation activities have to be separated. While the first Directive required an administrative unbundling, only obliging companies to present a separate balance sheet for each activity, the second goes a step further requiring legal unbundling. Transmission and distribution companies respectively have to apply legal unbundling from 1 July 2004 and 2007.

Even though the Directive 96/92/EC was implemented into national legislation using different approaches and different paces, the most important options of the Directive were chosen in a similar way throughout the Member States resulting in similar arrangements $^{5}$. The second Directive 2003/54/EC can be characterized by shorter term deadlines and less freedom which should result in more convergence between Member States. Note however that the Directives do not provide any explicit provisions on the regulation of cross-border electricity trade. This has resulted in different kinds of bilateral cross-border access arrangements. Therefore, Regulation 1228/2003 issued together with the Directive 2003/54/EC in 2003, establishes a compensation mechanism for cross-border flows of electricity, the setting of harmonized principles on cross-border transmission charges and the allocation of available capacities on interconnections between national transmission systems ${ }^{6}$. Note also that Directives and Regulation refrain from designing a concrete market. The IEM market architecture that resulted from this context, is discussed in the next section.

\section{MARKET ARCHITECTURE}


There is no general definition for the term market ${ }^{7}$ but at least two market categories are needed to describe the IEM, being the entire market and the component 'submarkets' of the entire market. Market architecture discusses the submarkets and the linkages between them (Figure 1).

The entire IEM is first of all divided in submarkets according to the control zones of the different transmission system operators, which often coincide with national borders. In general, the zonal Member State markets can be further divided in a wholesale, a balancing and a retail market. In what follows the wholesale and balancing markets are discussed.

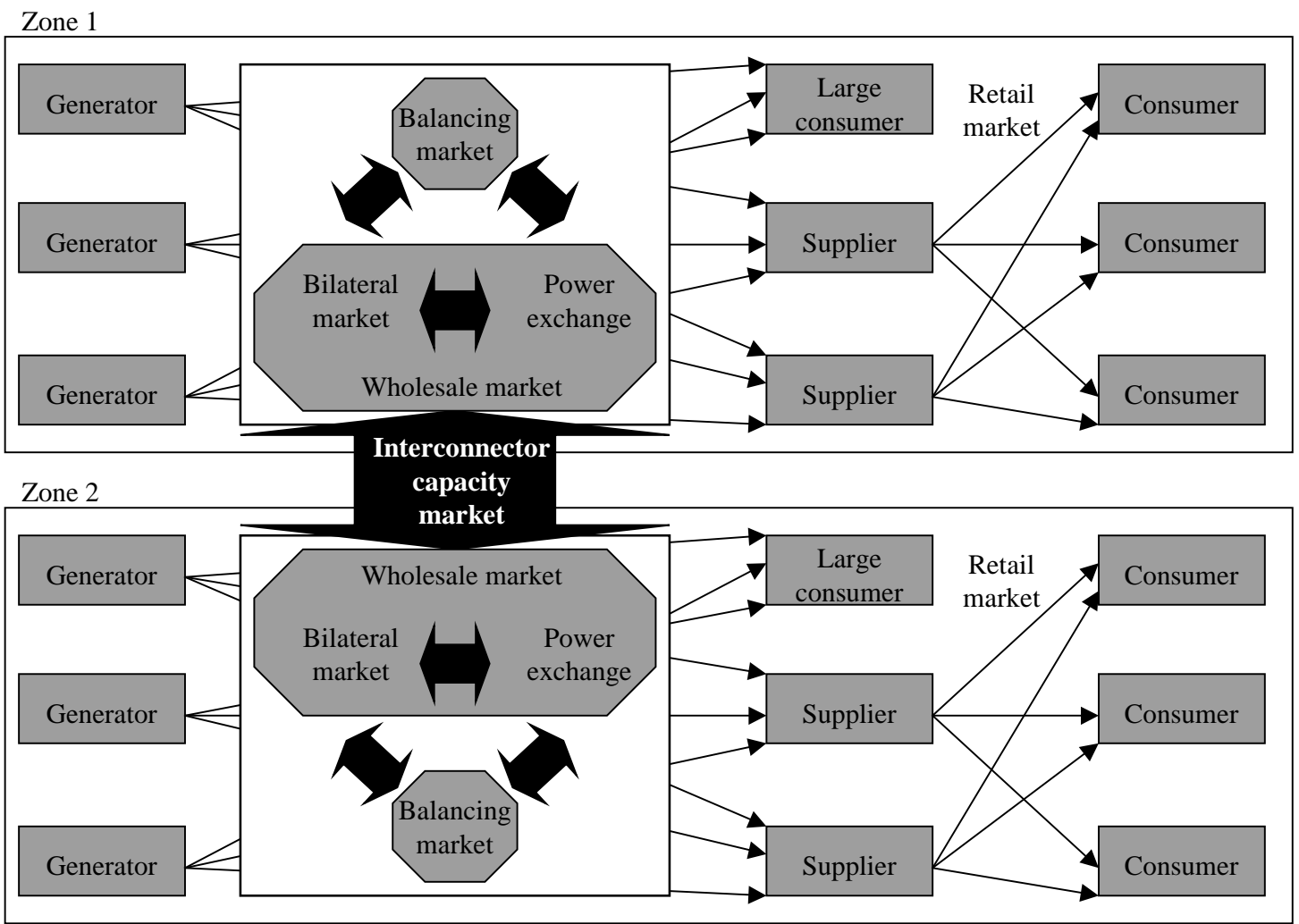

Figure 1: IEM market architecture

Most wholesale trade volume in the IEM is traded bilaterally in forward and over-thecounter (OTC) type of markets. Suppliers buy in advance using long-term and forward contracts to cover their consumption portfolio. As real consumption is not completely predictable and electric energy cannot be stored, there is also a need for additional daily and even hourly contracts in spot markets. 
Transaction costs of fine tuning a portfolio via OTC type of spot markets are high because of the search costs of finding an adequate counter party, the bargaining costs and the problem of non-anonymity as the confidentiality of each company's position is valuable close to real time. Therefore, a mixture of private and public initiatives of generators, suppliers and transmission system operators has lead to the creation of power exchanges in most Member States. Power exchanges are trading platforms operating day-ahead (one day before delivery) and facilitating anonymous trade in hourly and multi-hourly contracts called block orders. Even though power exchanges only attract a relative small fraction of total trade, their public hourly price index serves as a reference for the contracts negotiated in forward markets.

In other words, the zonal wholesale markets can be considered as a bilateral decentralized type of market because the only centralized part is voluntary. Note that zonal wholesale markets do not take into account intra-zonal transmission constraints. This is possible because Member States have decided to initially allow an unlimited use of the national grid for wholesale trade, and to alleviate intra-zonal congestion real time. The zonal wholesale markets are linked by interconnector capacity markets, as national grids in Europe are well developed but interconnection between these grids is relatively weak so that cross-border transfers have to be limited. On all borders, a method has been implemented to allocate cross-border transfer capacities, taking into account inter zonal or cross-border transmission constraints.

Wholesale trade stops at gate closure when Access Responsible Parties (ARP's) submit their unit commitment program to the Transmission System Operator (TSO). The TSO balances load and generation in the control zone at real time, taking into account intra-zonal transmission constraints and consequently settles the costs with the unbalanced ARP's. For this purpose, the TSO procures regulating and reserve power, being dispatchable generation and interruptible loads. TSO's in Europe procure balancing power in centralized markets ranging from mandatory to purely commercial market types and from day-ahead offering to long term tendering ${ }^{8}$.

Payments for these balancing services are generally based upon availability and utilization, as the TSO procures options or rights to call upon regulating and reserve power with a certain strike price. Apart from a few exceptions, there is no link between 
zonal balancing markets. Via the Union for the Co-ordination of Transmission of Electricity (UCTE), an association of continental European countries whose grids are interconnected and operate synchronously, there is for instance an arrangement for primary frequency control ${ }^{9}$. Note that some but not all of the countries part of this arrangement are also Member States of the EU. In other words, even though there is a potential benefit in linking balancing markets, at this moment the potential cannot be materialized, as they are organized nationally and are not accessible via the interconnector capacity markets.

Ancillary or system services, other than balancing services like voltage control and black-start capabilities that are also procured by the TSO and delivered real time have not been discussed, as they are typically local so that there is no linking potential.

\section{STATUS OF THE IEM}

The status of the IEM can be measured on the one hand by the implementation status of the market framework being the general market conditions laid down in the Directive 2003/54/EC and Regulation 1228/03, and on the other hand by the market structure, development and organization in the European Union.

For an overview of market opening, third party access, unbundling, etc per Member State, the fourth benchmark report from the European Commission ${ }^{10}$ can be studied. Even though Member States are moving in the right direction, some are rather slow in implementing the Directive 2003/54/EC completely. As a consequence, 8 Member states have recently received warnings from the Commission. Moreover, market based methods for the allocation of interconnector transfer capacity should have been in place since July 2004 to be in line with Regulation 1228/03, while 13 of the 25 most congested interconnections still had non-market based methods ${ }^{11}$ in 2004 . Note that the text and guidelines have direct effect and that national regulatory decisions non compliant with Regulation 1228/03 constitute an infringement. A recent paper of ${ }^{12}$, clearly lists the borders with allocation methods that are non compliant with Regulation 1228/03.

The electricity market structure can be characterized by consolidation and reverticalization. Since the liberalization, the industry has moved from a situation with 1 
(or more) national champion(s) per country to a situation with a few big European players present in several countries, the biggest 7 being EDF, Enel, EON, RWE, Vattenfall, Endessa and Electrabel. Since the collapse of Enron, there has been a move away from light asset companies and towards companies that integrate generation with supply activities and also companies that integrate gas supply activities with electricity generation. Given this market structure, market monitoring will be crucial to guarantee fair trade $\mathrm{e}^{13}$.

The market is clearly not fully developed yet (Figure 2). The European Commission holds a OTC volume benchmark of 10 times consumption ${ }^{14}$, to which only the UK market comes close. It is normal that power exchanges (PX) only attract a fraction of the consumption and an even smaller fraction of total trade, but it can be questioned whether current trading volumes yield a reliable price reference. Without a reliable and stable price reference, financial markets being quasi non-existent for the moment, will be slow in development and will have expensive risk premiums.
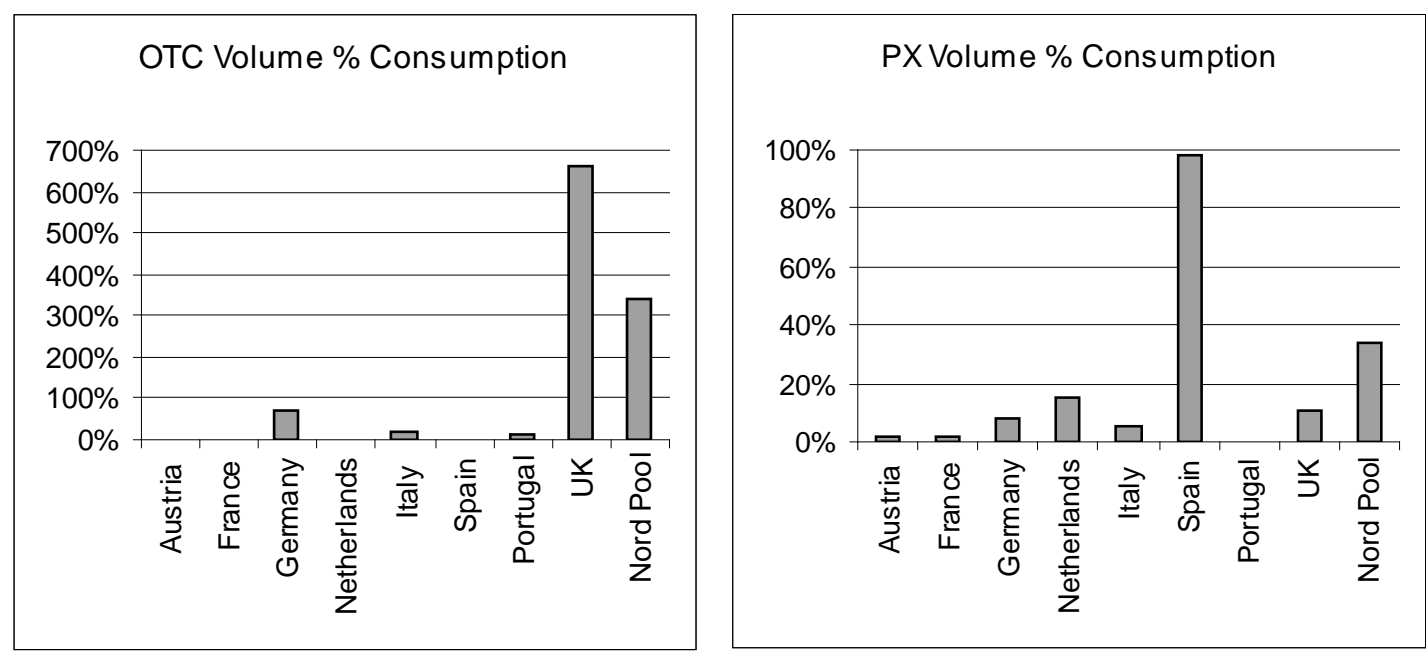

Figure 2: Wholesale market development (EC, 2005a)

Market design is a very controversial subject, especially in case of electricity markets. ${ }^{15}$ There is no consensus among academics on the best collection of submarkets from which to construct an electricity market, neither on which submarket should be of which type or on how a certain submarket type should be implemented. It is said that best design is discovered by experiment. In case of the IEM, this experiment has lead to the market architecture as discussed in section 3 with different 
Member State submarkets having similar market architectures that are linked by interconnector transfer capacity markets.

\section{VIEWPOINT ON FUTURE DEVELOPMENT OF THE IEM}

In this section, it is argued that the way forward for the creation of a single IEM is to pay more attention to improving the links between Member State submarkets. First, this will require extra investments in interconnector transfer capacity (section 5.1). Second, optimal use of the existing network infrastructure and future infrastructure expansions is required so that Member State markets start converging into a single market. The authors see 2 possible stages to improve the links between the Member State submarkets (section 5.2).

\subsection{Bottleneck investment}

Regulation of transmission investments is important in Europe because the merchant investment model is not considered suitable as a general model for interconnector investments. ${ }^{16}$ In what follows both European measures to stimulate regulated crossborder transmission investments are discussed, being the Trans-European Energy Networks Program (TEN-E) and Regulation 1228/2003.

In 1996, bottlenecks of common interest were listed for the first time via the TEN-E program. Investment projects alleviating these bottlenecks have the first call on TEN-E funding. The list has been revised three times in 1997, 1999 and 2003. In December 2003 , the Commission proposed to update the lists of priority projects to take into account the EU enlargement in May $2004^{17} .9$ axes, being clusters of priority projects, have been determined. ${ }^{18}$ The program generally co-finances feasibility studies up to 50 $\%$ of their budget. In a limited number of cases (3 since 1998), it also co-finances investment projects up to $10 \%$ of their budget. ${ }^{19} \mathrm{~A}$ survey conducted by $\mathrm{EC}^{20}$, concludes that the TEN-E financing has a relatively minor effect on the overall budget of the actual investment projects, but can act as an important stimulator at an early and risky stage of the project. 
Regulation 1228/2003, Article 6 states that any revenues resulting from the allocation of interconnection capacity, called Congestion Revenue CR, can only be used for one or more of the following purposes:

(a) guaranteeing the actual availability of the allocated capacity;

(b) network investments maintaining or increasing interconnection capacities;

(c) as an income to be taken into account by regulatory authorities when approving the methodology for calculating network tariffs, and/or in assessing whether tariffs should be modified.

CR results from binding transmission constraints. Such binding constraints limit the value that can be created by exchanging electric energy across borders, the lost value being the Socio-economic Cost of Congestion (SCC). Note that in the short run, the cost of congestion for market parties is CR+SCC because congestion revenue received by the TSO, is paid by the market parties. By using option (c), which is reimbursing $C R$ to market parties via a transmission tariff reduction, the cost of congestion for market parties can be reduced to SCC.

Note that $\mathrm{CR}$ is the result of locational signals given to the market parties in case of congestion. Because load and generation are not very mobile in the case of electric energy, these locational signals will not easily alleviate SCC. Therefore, it can be in the benefit of the market to use $\mathrm{CR}$, to reduce SCC by investing in bottlenecks, i.e. using option (b) instead of option (c). However, there is a theoretical optimal point of congestion where the cost of remedying offsets the benefit. Given the weak interconnectivity at the moment in Europe, it is in the benefit of market parties to use CR to reduce SCC (option (b)), but regulators are often biased towards a short term tariff reduction (option (c)).

The Council of European Energy Regulators (CEER) has already stressed the importance of regulatory guidelines for evaluating such regulated bottleneck investment projects. ${ }^{21}$ Leaving the options open, without guidelines, is causing underinvestment. Moreover, investment projects presented to the national regulator by the TSO tend not to contain an assessment of the common European interest involved, even if they have received funding on that basis. It is the authors' opinion that more 
investment coordination is clearly necessary, either pushed by European regulation or driven by coordinated regulatory actions. ${ }^{22}$

\subsection{Improving linkage between Member State submarkets in 2 stages}

At this moment, the only extra cost of exchanging energy across borders is the price of interconnector transfer capacity. Since 2002, interim inter-TSO compensation mechanisms have been in place, which compensate TSO's for transits, avoiding pancaking of national network access tariffs, and successively reducing transaction based access charges. ${ }^{23}$ Regulation 1228/2003 also forces the allocation of interconnector transfer capacity to be market based, meaning that the situation should be as illustrated in Figure 3 ('current situation'). As discussed in section 4, on some borders a market-based method is not yet in place.

In Stage 1 (Figure 3), links between Member State submarkets should be improved by implicitly allocating at least part of the available transfer capacities via power exchanges so that their day-ahead energy auctions are directly coupled. By coupling the day-ahead auctions, liquidity increases and price volatility decreases one day before delivery. A recent study commissioned by the European Commission concludes that the introduction of implicit allocation methods for interconnector transfer capacity could effectively increase economic efficiency. ${ }^{24}$ By eliminating the information lag between interconnector transfer capacity markets and wholesale energy markets, some possibilities for exercising market power are mitigated and energy markets are better coordinated. Another benefit is that Stage 1 implies that at least part of the transfer capacities are allocated coordinated over several borders.

Currently, total available transfer capacity on most borders is allocated on different time horizons, mostly yearly, monthly and daily. Initially, only daily transfer capacity could be allocated by power exchanges. This initial arbitrary fractioning of the total available transfer capacity between power exchanges and capacity markets can consequently be replaced by a fractioning based on the observed transfer capacity prices and day-ahead energy price differences. Another possibility is to allocate all transfer capacity via the power exchanges as already done in the Scandinavian countries. It is important to have a fixed amount of transfer capacity to be allocated via power exchanges as variations in the available transfer capacity can cause zonal 
electric energy price difference variations and extra uncertainty, which can partly offset the stabilizing effect of an implicit allocation. If market parties are allowed to bid explicitly on the capacity that is available day-ahead for implicitly allocation, there is a similar destabilizing effect on energy prices. Moreover, offering this flexibility to market parties actually implies that the opportunity for market power abuse that an implicit allocation is supposed to mitigate, is retained. In other words, explicit allocation should not be mixed with implicit allocation day-ahead on the same border. ${ }^{25}$

In Stage 1, coordination and harmonization are mostly on the shoulders of power exchanges. Some initiatives are already in the pipeline on a regional scale. The pragmatic regional approach is supported by DGTREN that organized the first regional mini-fora on regional coordinated market based allocation mechanisms for crossborder trade in 2004-2005.

In Stage 2 (Figure 3), links between Member State submarkets should be further improved by organizing both the procurement of balancing power and the real time balancing across borders. Stage 2 has a lot of potential because the market for standardized balancing products is tighter than for electric energy. All generation units are able to deliver electric energy, but not all of them are dispatchable and only some of them have a quick enough response time. Therefore, pooling these units in a crossborder balancing market has a lot of potential, even if transmission constraints have to be taken into account. Stage 2 could initially be implemented by using the transfer capacity which has not been used by the wholesale markets. Note that even if all transfer capacity is used in one direction, balancing is still possible in the opposite direction. Consequently, a fraction of the available transfer capacity could be reserved for balancing purposes, similar to the UCTE arrangement for primary frequency control. Note that TSO's procure options on balancing power so that transfer capacity reserved for the balancing market is not necessarily used. However, reserving transfer capacity for balancing can be interesting if zonal balancing prices are less stable and deviate more extremely across borders than the day-ahead electric energy prices.

In Stage 2, coordination and harmonization are mostly on the shoulders of transmission system operators. This stage is more difficult to implement due to several reasons. First, balancing arrangements differ widely among Member States and are not always as transparent. Second, unbalance settlement periods differ widely from 1 
hour in some Member States till 15 minutes in other. Third, gate closure in some Member States is day-ahead, while in other Member States trade is possible up to 1 hour before delivery. Note that the possibility of intraday trade should become standard so that market parties have more opportunities to avoid unbalances. In other words, Stage 2 offers the opportunity to consolidate best balancing practices to the European level.

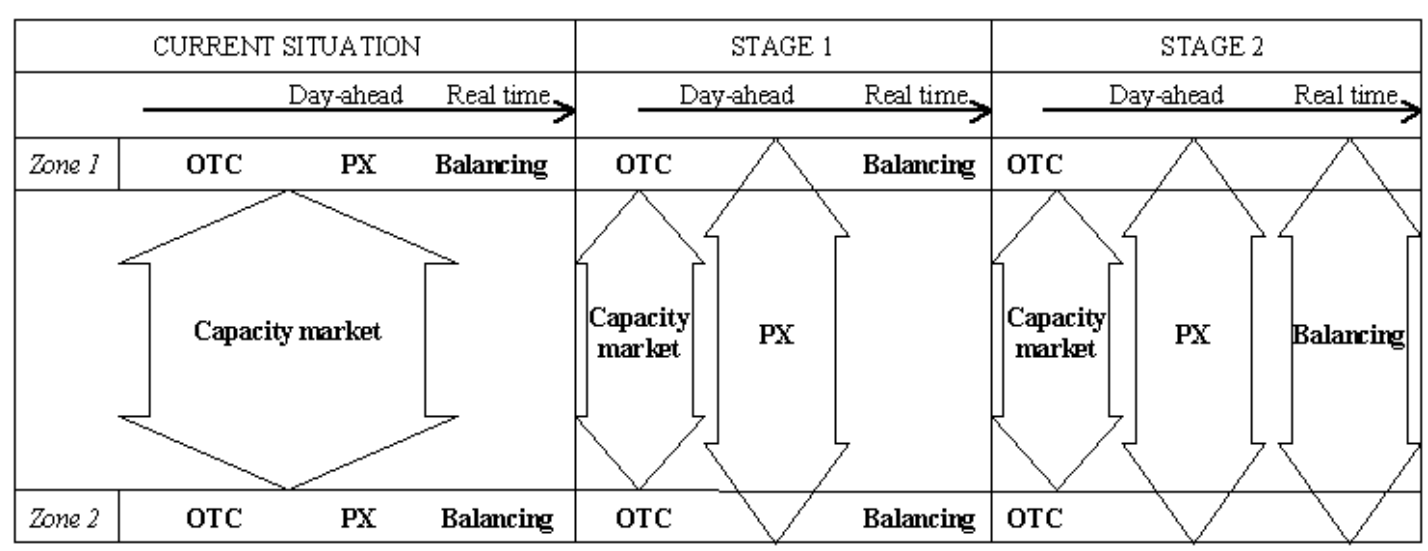

Figure 3: 2 stages towards improved linkage of Member State wholesale markets (OTC + PX) and balancing markets

\section{CONCLUSIONS}

Even though, the Directives refrain from designing a concrete market architecture, the IEM consists of 25 Member State submarkets with similar architectures. Wholesale markets are mainly bilateral, but in most Member States, there is the possibility for anonymous auction trade organized by power exchanges one day before delivery. This market organization differs from most other liberalized markets world wide, where authorities, inspired by the pools long time used by vertically integrated utilities to reach an optimal technical dispatch, have often chosen to design a mandatory power pool for wholesale trade.

The authors argued that at this moment market structure is more European than market architecture. The industry has consolidated into a few big European players, while the market consists of Member State submarkets weakly linked by interconnector capacity markets. While it is true that best market design is discovered by experiment, at this stage of the IEM development it is time to consolidate best practices to the European level. A vehicle for this harmonization is improving the links 
between submarkets gradually. Two stages for improvement were introduced that can first be implemented on a regional level and grow into a European scale system. In a first stage, power exchanges should work coordinated, while in a second stage, transmission system operators should coordinate their balancing markets. There are some regional developments in this direction, meaning that at this moment it is difficult to assess whether more European regulation will be necessary.

However, European regulation or coordinated regulatory actions are clearly necessary to coordinate bottleneck investments. It has been stressed that the current regulatory framework is leading to underinvestment in the grid, while technical bottlenecks are an important obstruction for the creation of a single Internal Electricity Market in Europe.

\section{Endnotes:}

1. For a discussion on liberalization and privatization, see for instance Littlechild S. C., 2001. Electricity: Regulatory developments around the world, available at: www.econ.cam.ac.uk/electricity/publications/index.htm and Newbery, D. M., 2001. Privatization, restructuring and regulation of network utilities, Cambridge, MA, MIT press.

2. Wolak F. A., 2003. Diagnosing the California Electricity Crisis, The Electricity Journal, Volume 16, Issue 7, pp 11-3.

3. Directive 96/92/EC, 1996. of the European Parliament and of the Council of 19 December 1996 concerning common rules for the internal market in electricity. Official Journal of the European Union, 1997, L27, 20-29 and Directive 2003/54/EC, 2003. of the European Parliament and of the Council of 26 June 2003 concerning common rules for the internal market in electricity and repealing Directive 96/92/EC. Official Journal of the European Union, L 176, 2004, 37-55.

4. Roggenkamp M. M., Boisseleau F., 2005. The liberalization of the EU electricity market and the role of power exchanges, in Roggenkamp M. M., Boisseleau F. (eds), The regulation of power exchanges in Europe, Energy\&Law sersies - volume, 312 pages.

5. Bergeman L., Brunekreeft G., Doyle C., von der Fehr N-H. M., Newbery D. M., Politt, Vaitlingham R., 1999. A European market for electricity: monitoring European Regulation, Centre for econmic policy research, London www.cepr.org and SNS, Stochholm www.sns.se ISBN: 189812842 1. Glachant J-M, 2001. Attractiveness and accessibility of 16 electricity markets in Western Europe, in E. Hope, L. Melamed and 
M. Lychagin (eds.), Electricity economics: policies, Russion academy of sciences, pp. 187-208.

6. Regulation $1228 / 2003$ of the European parliament and of the council of 26 June 2003 on conditions for access to the network for cross-border exchanges in electricity, Official Journal of the European Union, 2003, L 176/1, pp. 1-10.

7. Tirole, 1997. The theory of industrial organization, Cambridge, MA: the MIT Press.

8. European Transmission System Operators ETSO, 2003. Current state of balance management in Europe, available at: http://etso-net.org.

9. Union for the Co-ordination of Transmission of Electricity UCTE, 2004. Operation handbook: final draft load-frequency control, available at: www.ucte.org.

10. European Commission EC, 2005. Fourth benchmarking report, Annual Report on the Implementation of the Gas and Electricity Internal Market, Communication from the Commission, $\operatorname{COM(2004)~863,~available~at~http://europa.eu.int/comm/energy.~}$

11. European Transmission System Operators ETSO, 2004. An overview of current cross-border congestion management methods in Europe, available at http://etsonet.org.

12. European Regulators Group for Electricity and Gas ERGEG, 2005. Global assessment of the results of the 1st series of mini fora on congestion management and potential impacts on the draft guidelines, available at: http://www.ergeg.org.

13. Bower J., Bunn D. W., Wattendrup C., 2001. A model-based analysis of strategic consolidation in the German electricity industry, Energy Policy 29, 987-1005.

14. European Commission EC, 2005. Fourth benchmarking report, Annual Report on the Implementation of the Gas and Electricity Internal Market, Communication from the Commission, $\operatorname{COM(2004)~863,~available~at~http://europa.eu.int/comm/energy.~}$

15. See for instance Stoft, S., 2002. Power system economics, designing markets for electricity, IEEE Press, 496pp and Wilson R., 1999. Market architecture, working paper, graduate school of business, Stanford University, available at: http://facultygsb.stanford.edu/wilson.

16. Directorate-General Energy and Transport DGTREN, 2004a. strategy paper, medium term vision for the internal electricity market, available at http://europa.eu.int/comm/energy.

17. European Commission EC, 2003. Proposal for a decision of the European Parliament and of the Council laying down guidelines for trans-European energy networks and repealing Decision Nos 96/391/EC and 1229/2003/EC, COM(2003) 742 final, 10.12.2003. 
18. For detailed information on the priority projects objectives and main elements, see the brochure of Directorate-General Energy and Transport DGTREN, 2004b, Brochure Trans-European Energy Networks: TEN-E Priority projects, available at: http://europa.eu.int/comm/energy.

19. European Commission EC, 2005. List of projects financed through the TransEuropean Energy Networks (TEN-E) program in 1995-2003 available at: http://europa.eu.int/comm/energy.

20. European Commission EC, 2004. Mid-term evaluation of the TEN-E program 2000-2006, available at http://europa.eu.int/comm/energy.

21. Council of European Energy Regulators CEER, 2003. CEER's position paper on regulatory control and financial reward for infrastructure.

22. Meeus L., Purchala K., Degli Esposti C., Van Hertem D., Belmans R., 2005. Regulated cross-border transmission investment in Europe, working paper, preprint available at: leonardo.meeus@esat.kuleuven.ac.be.

23. For a discussion and history of the compensation mechanism, see European Transmission System Operators ETSO, 2005. Cross-border compensation mechanism 2002-2005, available at: http://etso-net.org.

24. European Commission EC, 2004. Study commissioned by DGTREN by Fontier economics and Consentec: Analysis of cross-border congestion management methods for the EU internal electricity market, Final report, available at: http://europa.eu.int/comm/energy.

25. As EEX seem to suggest, 2005. Open market coupling, presentation of German power exchange at the DGTREN mini fora on regional coordinated market based allocation mechanisms for cross-border trade, available at: http://europa.eu.int/comm/energy. 


\section{BIOGRAPHIES}

Leonardo Meeus received the M.S. degree in commercial engineering in 2002 from the K.U.Leuven. He is a member of the KULeuven Energy Institute and of the Electrical Energy research group (ELECTA) of the department of Electrical Engineering of the KULeuven, where he is working towards a Ph.D. on electrical energy auctions. His research interests include electricity markets, power systems, security of supply and sustainable energy.

Konrad Purchala graduated in 1999 as electrotechnical engineer from Warsaw University of Technology, Poland. Since 2000 he is working as a research assistant at Katholieke Universiteit Leuven (K.U.Leuven). He is a member of KULeuven Energy Institute and Electrical Energy research group (ELECTA) of the department of Electrical Engineering, where he is writing his Ph.D. on technical and economic aspects of congestion management. His research interests include congestion management, techno-economic aspects of power systems and electricity markets.

Ronnie Belmans received the M.S. degree in electrical engineering in 1979 and the Ph.D. degree in 1984, both from the K.U.Leuven, Belgium, the Special Doctorate in 1989 and the Habilitierung in 1993, both from the RWTH, Aachen, Germany. Currently, he is a full professor with the K.U.Leuven, teaching electric power and energy systems. His research interests include techno-economic aspects of power systems, power quality and distributed generation. He is also guest professor at Imperial College of Science, Medicine and Technology, London-UK. Since June 2002 he is chairman of the board of directors of ELIA, the Belgian transmission grid operator. 